\title{
Heavy Metals Monitoring in Sediments from Lerma River in West-Central Mexico
}

\section{Héctor Hernández-Mendoza1,2*, María Judith Ríos-Lugo33, Elizabeth Teresita Romero-Guzmán1, Lázaro Raymundo Reyes-Gutiérrez ${ }^{4}$, Michael E. Ketterer ${ }^{5}$}

\author{
${ }^{1}$ Instituto Nacional de Investigaciones Nucleares, Ocoyoacác, México \\ ${ }^{2}$ Universidad del Centro de México, San Luis Potosí, México \\ ${ }^{3}$ Universidad Autónoma de San Luis Potosí, San Luis Potosí, México \\ ${ }^{4}$ División of Ciencias Básicas e Ingeniería, Departmentof Recursos de la Tierra, Universidad Autónoma Metropolitana-Lerma \\ (UAM-L), Lerma, México \\ ${ }^{5}$ Department of Chemistry, Metropolitan State University of Denver, Denver, USA \\ Email: ^hector.hernandez520@gmail.com,judith.rios@uaslp.mx, elizabeth.romero@inin.gob.mx, \\ 1.reyes@correo.ler.uam.mx,mkettere@msudenver.edu
}

How to cite this paper: HernándezMendoza, H., Ríos-Lugo, M.J., RomeroGuzmán, E.Y., Reyes-Gutiérrez, L.R. and Ketterer, M.E. (2018) Heavy Metals Monitoring in Sediments from Lerma River in West-Central Mexico. American Journal of Analytical Chemistry, 9, 77-87. https://doi.org/10.4236/ajac.2018.92007

Received: November 7, 2017

Accepted: February 10, 2018

Published: February 13, 2018

Copyright ( $) 2018$ by authors and Scientific Research Publishing Inc. This work is licensed under the Creative Commons Attribution International License (CC BY 4.0).

http://creativecommons.org/licenses/by/4.0/

\begin{abstract}
The aim of this work was to carry out monitoring of some elements considered toxic in sediments from Lerma River. An analytical method was optimized in our laboratory for quantification of nickel (Ni), cobalt (Co), manganese $(\mathrm{Mn})$, arsenic $(\mathrm{As})$, chromium $(\mathrm{Cr})$ and lead $(\mathrm{Pb})$ by using Inductively Coupled Plasma Optical Emission Spectrometry (ICP-OES). Ten sediments were collected along the Lerma River at variable distances and at $20 \mathrm{~cm}$ depth. Samples were heated to $60^{\circ} \mathrm{C}$ to dryness, followed by separation of particle size using a $74-\mu$ No. 200 mesh for homogeneity purposes. $0.2 \mathrm{~g}$ of sample underwent microwave-assisted acid digestion, followed by plate evaporation. The samples were dissolved in $10 \mathrm{~mL}$ with $\mathrm{HNO}_{3}$ at $5 \% \mathrm{v} / \mathrm{v}$ for ICP-OES analysis. A certified reference material (CRM 8704) was used to evaluate the method's accuracy and precision. The method showed linearity, precision, accuracy, and limits of quantification and detection acceptable for protocol validation of analytical method. The average results obtained in recovery of CRM 8704 were $~ 90 \%$ and precision was below $7 \%$ for all elements. Levels concentration of $\mathrm{As}, \mathrm{Cr}, \mathrm{Pb}$ show high pollution in $\mathrm{A} 1, \mathrm{~A} 7$ and $\mathrm{A} 8$ sites. Therefore, $\mathrm{Co}, \mathrm{Mn}$ and $\mathrm{Ni}$ can be considered in this study as normal values. In conclusion, concentration levels of $\mathrm{As}, \mathrm{Cr}, \mathrm{Pb}$ in sediments were high according to US-EPA and NOM-147-SEMARNAT/SSA1-2004. The presence of these heavy metals in Lerma River could be due mainly for the emitted from industries, such as pharmaceutical, automotive, metal mechanics and tannery, and urban residual water. Finally, the method developed using ICP-OES has
\end{abstract}


enabled monitoring of these elements in sediments from Lerma River, with possible applications in a routine analytical laboratory.

\section{Keywords}

ICP-OES, Lerma River, Sediments, US-EPA,

NOM-147-SEMARNAT/SSA1-2004

\section{Introduction}

Mexico does not have strict regulations in place to prevent the discharge of toxic waste produced by industries. Such is the case of the Lerma-Chapala hydrological system, which constitutes one of the most important watersheds in Mexico. The region is drained by the Lerma and Santiago (2118 km long) rivers as main collectors. The high watershed of Lerma River is located in the State of Mexico (Figure 1), and it is subdivided in three portions: 1) high course, 2) medium course, and 3) low course, with a total length of $175 \mathrm{~km}$. The high course (60 $\mathrm{km}$ ) corresponds to the region near Toluca city. In the past, the Lerma River ecosystem included different kinds of fish, crustaceans, and marine bird species, which are no longer found there. Demographic growth and concomitant industrialization have generated serious pollution problems in the Lerma River [1]. Some published studies [2] [3] mention that the Lerma River is considered one of the most polluted in Mexico due to industrial discharges and untreated urban wastewater. In general, these waters contain pesticides, herbicides, heavy metals, and complex organic species (cosmetic products or pharmaceutical industry waste) that are widely studied by researchers from Mexico. The presence of heavy metals is caused by human activities and their health effects have been known for some time; therefore, exposure to heavy metals has been evident, and is even increasing in some parts of the world. The main threats to human health from heavy metals are associated with exposure to lead $(\mathrm{Pb})$, nickel $(\mathrm{Ni})$, cadmium (Cd), mercury (Hg), manganese (Mn), arsenic (As) [4] [5]. These metals have been extensively studied and their effects on human health regularly reviewed by international bodies such as the World Health Organization (WHO) [6] [7] [8] [9]. Additionally, the United States Environmental Protection Agency 2011 has recently shown great interest in the monitoring heavy metals, such as $\mathrm{Pb}, \mathrm{Hg}, \mathrm{Cr}, \mathrm{Cd}, \mathrm{As}$ in water, food, soil, and sediments [10] [11] [12] because of their high toxicity to humans in small concentrations. Heavy metals are of particular interest to environmental researchers worldwide due to their major effects on environmental quality. The main sources of heavy metals pollution in the environment are industrial effluents, anthropogenic activities, and sewage discharges, among others. Generally, industrial and domestic effluents are unwanted because they have several classes of pollutants such as several types of synthetic chemical, hydrocarbons and heavy metals [13] [14]. 


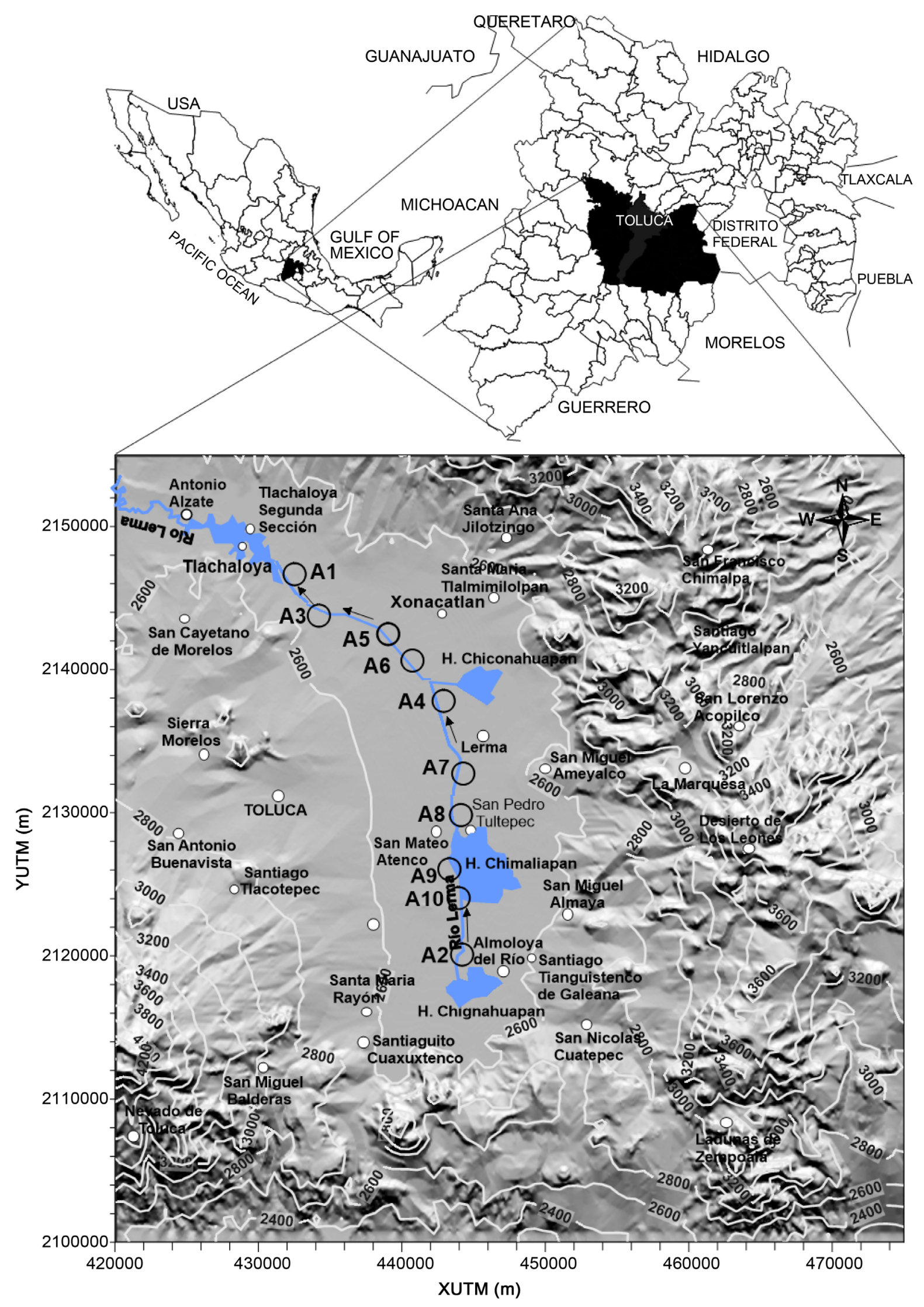

Figure 1. Location of Lerma River, México and locations where sadiments samples were colleted. 
The major analytical methodologies of routine measurement of heavy metals in environmental samples have been by using Atomic Absorption Spectroscopy (AAS) [15], Atomic Fluorescence Spectrometry (AFS) [16] and X-ray fluorescence spectrometry (EDXRF) [3]. These techniques have shown excellent results in routine analysis due to their low cost, robustness, accuracy, and moderate accuracy. However, inductively coupled atomic emission spectroscopy (ICP-AES) and inductively coupled plasma optical emission spectrometry (ICP-OES) are the most powerful methods for the analysis of multi-elements at trace levels in solutions. Both techniques have had a clear role in the quantification of heavy metals because of their ease of use, high sensitivity, precision and relatively low interference. Due to these characteristics, ICP-OES or ICP-AES has been the analytical methods of choice for a wide range of complex samples. The key to these techniques is to focus on analysis of samples that have a high content of dissolved solids.

Detection limits of the ICP-OES can reach levels of $\mu \mathrm{g} \cdot \mathrm{L}^{-1}$ in different environmental samples or mining samples. The sensitivity showed by multi-elemental determination of ICP-OES is unmatched by other analytical techniques, such as the spectroscopic techniques (ASS, AFS or EDXRF).

On the other hand, a similar technique at ICP-OES and ICP-AES is mass spectrometry with inductively coupled plasma mass spectrometry (ICP-MS), which possesses the highest sensitivity in the analysis of heavy metals. However, ICP-MS only allows $2 \%$ of dissolved solids in comparison with ICP-OES that allows between $10 \%$ and $20 \%$. Both techniques are frequently utilized for the detection of heavy metals in environmental samples [17].

The aim of this work was to carry out the monitoring of heavy metals in sediments from the Lerma River by ICP-OES.

\section{Materials and Methods}

\subsection{Treatment of Samples}

The sediment sample data used in this study were collected in situ for analysis along the Lerma River at variable distances from the Almoloya del Río wetland $(\mathrm{A} 2=2, \mathrm{~A} 10=4, \mathrm{~A} 9=6, \mathrm{~A} 8=10, \mathrm{~A} 7=13, \mathrm{~A} 4=18, \mathrm{~A} 6=20, \mathrm{~A} 5=22, \mathrm{~A} 3=24$, and $\mathrm{A} 1=27 \mathrm{~km}$ ) to the Alzate dam (Figure 1). All samples were collected at a depth of $20 \mathrm{~cm}$ with a digger.

Ten samples of $2 \mathrm{~kg}$ of sediment were collected on the surface and placed in 1 $\mathrm{L}$ capacity glass jars (previously washed with $\mathrm{HNO}_{3}$ at $10 \% \mathrm{v} / \mathrm{v}$ ). The samples were kept at $-4^{\circ} \mathrm{C}$ in order to maintain the same chemical conditions of the container before the analysis. A representative composed sample was prepared to the each collected samples from the superficial zone. The samples were separated using a mesh No. 200 of $74 \mu$, for homogeneity purposes. Samples were heated at $60^{\circ} \mathrm{C}$ to dryness in plate to remove all the water, followed by oven drying at $90^{\circ} \mathrm{C}$ for $96 \mathrm{~h}$. Granulometric analysis determined that the granular materials are grouped as sand, silts, and clays, with the grain size tending to decrease 
towards the Alzate dam; thus, the sediment is considered to be a sandy loam soil with little clay content. The finest materials continue in suspension up to the curtain of the Alzate Dam. For treatment of samples, $0.2 \mathrm{~g}$ sample was added to $10 \mathrm{~mL}$ of high-purity $\mathrm{HNO}_{3}$ and $3 \mathrm{~mL}$ of concentrated $\mathrm{HF}$ were taken to acid digestion using the microwave system. Operational conditions and heating program used were following: ramp time of $20 \mathrm{~min}$ to reach $180^{\circ} \mathrm{C}$, then $30 \mathrm{~min}$ at $180^{\circ} \mathrm{C}$. After cooling the vessels to room temperature, they were vented and opened. In order to carry out ICP-OES analysis, samples were evaporated to dryness and dissolved in $25 \mathrm{~mL}$ of $\mathrm{HNO}_{3}$ at $2 \% \mathrm{v} / \mathrm{v}$. All samples were prepared in triplicates (sediments and reagent blanks). CRM 8704 was prepared 10 times for the purpose of validating the method.

\subsection{Equipments and Reagents}

ICP-OES from Thermo Jarrell-Ash, Atom Scan Avantage was used for the quantification of heavy metals. Aqueous samples were introduced with a peristaltic bomb and nebulized with a micro concentric nebulizer coupled to HF Resistant Ultem Cyclone Spray chamber. The solutions were prepared using analytical grade reagents $\left(\mathrm{HNO}_{3}, \mathrm{HF}\right.$ and standards solution) from Merck (Germany). High purity water was used to prepare solutions and rinsing vessels. Wavelength calibration of ICP-OES was performed using standard solution of $\mathrm{Ni}, \mathrm{Co}, \mathrm{Mn}$, $\mathrm{As}, \mathrm{Cr}$, and $\mathrm{Pb}$ that contained $1000 \mathrm{mg} \cdot \mathrm{L}^{-1}$. The method was optimized by using $500 \mathrm{mg} \cdot \mathrm{mL}^{-1}$ of each element. Certified Reference Material (CRM 8704, Buffalo River Sediment) was used for method validation. Yttrium (Y) was used at a concentration of $5 \mathrm{mg} \cdot \mathrm{L}^{-1}$ with internal standard. High purity water $(>18 \mathrm{M} \Omega / \mathrm{cm})$ was obtained from a Milli- $Q^{\circledR}$ Reference (Millipore México). Milestone Duopur (Milestone s.r.l., Italy) sub-boiling system was used for obtaining high purity acid. Certified Ar gas (99.996\%) was supplied by INFRA, S.A. de C.V. México. A microwave MARS6 (CEM, Matthews, North Carolina) was used for digestion of the samples.

\section{Results and Discussion}

\subsection{Optimization of Instrumental Conditions in the ICP-OES}

Measurements of heavy metals by ICP-OES are not easy due at that is difficult to have a spectral line completely free of spectral interference. Nevertheless, selection of spectra line with less intensity and a mathematical correction are alternatives for the method optimization for elements measure using ICP-OES [18]. So, the choice of wavelength and torch mode, axial or radial, for the determination of a specific analyte is imperative, in order to prevent spectral lines from overlapping. Moreover, $\mathrm{Y}$ is a good internal standard because it helps in the decreasing effect the intense effects caused by matrix interference. Also, Y improving the precision of analytical signals, particularly for low concentration of heavy metal in solution.

Optimized parameters for carrying out the analysis of $\mathrm{Ni}, \mathrm{Co}, \mathrm{Mn}, \mathrm{As}, \mathrm{Cr}$, and 
$\mathrm{Pb}$ are shown in Table 1 . In the wavelength of emission at $186.231 \mathrm{~nm}$ there is an emission interference of aluminium $(\mathrm{Al})$ with lead $(\mathrm{Pb})$ that it is shown at $220.353 \mathrm{~nm}$. The interference has been used to avoid a mathematical correction, where the values of the constants of $\mathrm{Al}$ were: $\mathrm{K} 1=0.000542 \mathrm{X}$ [Al] and $\mathrm{K} 2=$ $0.00008 \mathrm{X}$ [Al]. These constants are of a polynomial equation of two grades, which help correct the interference of $\mathrm{Al}$ into $\mathrm{Pb}$.

\subsection{Method Validation}

Calibration curves were prepared at a range concentration of 0.1 to $5 \mu \mathrm{g} \cdot \mathrm{mL}^{-1}$. Table 2 shows the average results of calibration curves for each element over four days, where the linearity in terms of linear regression was $\sim 0.99$ for each element. Limits of quantification were calculated as suggested by [19]: LOQ $=5$ $\mathrm{X}$ LOD, where LOD $=(3 \times \mathrm{RSD} \times \mathrm{BEC}) / 100$. Where BEC corresponds to the background equivalent concentration, which was determined experimentally using optimized conditions. RSD is the Relative Standard Deviation of $n=5$,

Table 1. Instrumental parameters of ICP-OES.

\begin{tabular}{cc}
\hline RF Power (Watts) & 1150 \\
High Voltage (v) & 650 \\
Integration Time (sec) & 15 \\
Auxiliary Argon Flow Rate $\left(\mathrm{L} \cdot \mathrm{min}^{-1}\right)$ & 1.5 \\
Plasma Argon Flow Rate $\left(\mathrm{L} \cdot \mathrm{min}^{-1}\right)$ & 15 \\
Nebulizar Argon Flow Rate $\left(\mathrm{L} \cdot \mathrm{min}^{-1}\right)$ & 0.9 \\
Pump Rate (rpm) & 15 \\
Scan Parameter & Scan 1 \\
\hline \multicolumn{1}{c}{ Analytical Wavelength $(\mathrm{nm})$} & \\
\hline $\mathrm{Al}(\mathrm{nm})$ & 186.231 \\
$\mathrm{As}(\mathrm{nm})$ & 189.042 \\
$\mathrm{Cr}(\mathrm{nm})$ & 205.552 \\
$\mathrm{~Pb}(\mathrm{~nm})$ & 220.353 \\
$\mathrm{Ni}(\mathrm{nm})$ & 231.605 \\
$\mathrm{Mn}(\mathrm{mn})$ & 257.621 \\
$\mathrm{Co}(\mathrm{mn})$ & 230.787 \\
\hline
\end{tabular}

Table 2. Calibration curves obtained with ICP-OES for four days.

\begin{tabular}{ccccc}
\hline Element & $\mathrm{r}^{2}$ & Equation & LOD $\left(\mu \mathrm{g} \cdot \mathrm{mL}^{-1}\right)$ & LOQ $\left(\mu \mathrm{g} \cdot \mathrm{mL}^{-1}\right)$ \\
\hline $\mathrm{Ni}$ & 0.9987 & $\mathrm{y}=0.9915 \mathrm{x}-0.0075$ & $0.021 \pm 0.002$ & $0.095 \pm 0.007$ \\
$\mathrm{Co}$ & 0.9998 & $\mathrm{y}=0.9991 \mathrm{x}+0.0031$ & $0.085 \pm 0.009$ & $0.310 \pm 0.015$ \\
$\mathrm{Mn}$ & 0.9998 & $\mathrm{y}=1.001 \mathrm{x}-0.0080$ & $0.015 \pm 0.002$ & $0.069 \pm 0.005$ \\
$\mathrm{As}$ & 0.9996 & $\mathrm{y}=1.005 \mathrm{x}-0.0051$ & $0.0589 \pm 0.015$ & $0.191 \pm 0.009$ \\
$\mathrm{Cr}$ & 0.9998 & $\mathrm{y}=0.9951 \mathrm{x}-0.0099$ & $0.0015 \pm 0.0003$ & $0.052 \pm 0.004$ \\
$\mathrm{~Pb}$ & 0.9998 & $\mathrm{y}=0.9956 \mathrm{x}-0.0043$ & $0.0591 \pm 0.0011$ & $0.205 \pm 0.013$ \\
\hline
\end{tabular}


which was obtained from standard solution at $0.1 \mu \mathrm{g} \cdot \mathrm{mL}^{-1}$. In addition, precision for each element was less than 5\%. Accuracy and precision were evaluated with recovery of CRM 8704 and results obtained for each element were over 90\% and $<7 \%$, respectively (Table 3 ). The calculation of accuracy took into account the background of the reagent blanks.

\subsection{Sample Analysis}

The results of heavy metal measurements are shown in Table 4. Sites A1, A6, A7 and $\mathrm{A} 8$ are urban and rural wastewater drainage points. High concentrations of $\mathrm{Pb}$ were found at several sites, where A8 proved to be the most polluted site at $444.3 \pm 13.3 \mu \mathrm{g} \cdot \mathrm{g}^{-1}$ in comparison with site A3 (147.2 $\pm 6.1 \mu \mathrm{g} \cdot \mathrm{g}^{-1}$ of $\left.\mathrm{Pb}\right)$. High $\mathrm{Pb}$ pollution is explained in part by residual water from the city of Toluca unloading into the Lerma River; higher $\mathrm{Pb}$ content in cities comes from $\mathrm{Pb}$-emitting factories and in second order probably comes mainly from traffic and from paint, depending on circumstances. In this case it is an area with heavy vehicular traffic. In addition, the results show that other sites also have serious pollution problems with $\mathrm{Pb}$. These are Sites $\mathrm{A} 1, \mathrm{~A} 2$ and $\mathrm{A}$, where residual water from industries also has flows into Lerma River (A1 and A2). However, according to the values reported by USEPA [20] [21] all sites are highly polluted with $\mathrm{Pb}$ (Table 5). For As, the most polluted sites were A7, A8 and A1, where the

Table 3. Results obtain of recovery yield of CRM 8704 .

\begin{tabular}{cccc}
\hline Element & Reference Value $\left(\mu \mathrm{g} \cdot \mathrm{g}^{-1}\right)$ & Found Value $\left(\mu \mathrm{g} \cdot \mathrm{g}^{-1}\right)$ & \% Recovery Yield \\
\hline $\mathrm{Ni}$ & $42.9 \pm 3.7$ & $38.8 \pm 1.1$ & $90 \pm 0.03$ \\
$\mathrm{Co}$ & $13.5 \pm 0.43$ & $12.6 \pm 0.3$ & $93 \pm 0.02$ \\
$\mathrm{Mn}$ & $544 \pm 21$ & $524 \pm 14.0$ & $96 \pm 0.03$ \\
$\mathrm{As}^{*}$ & 17 & $16.1 \pm 0.5$ & $94 \pm 0.03$ \\
$\mathrm{Cr}$ & $121.9 \pm 3.8$ & $110.2 \pm 5.3$ & $91 \pm 0.04$ \\
$\mathrm{~Pb}$ & $150 \pm 17.0$ & $135.5 \pm 6.7$ & $90 \pm 0.04$ \\
\hline
\end{tabular}

Table 4. Results obtained for each elements in sediment samples $(n=5)$.

\begin{tabular}{ccccccc}
\hline Sites & As $\left(\mu \mathrm{g} \cdot \mathrm{g}^{-1}\right)$ & $\mathrm{Cr}\left(\mu \mathrm{g} \cdot \mathrm{g}^{-1}\right)$ & $\mathrm{Pb}\left(\mu \mathrm{g} \cdot \mathrm{g}^{-1}\right)$ & $\mathrm{Co}\left(\mu \mathrm{g} \cdot \mathrm{g}^{-1}\right)$ & $\mathrm{Mn}\left(\mu \mathrm{g} \cdot \mathrm{g}^{-1}\right)$ & $\mathrm{Ni}\left(\mu \mathrm{g} \cdot \mathrm{g}^{-1}\right)$ \\
\hline $\mathrm{A} 1$ & $1015.2 \pm 44.1$ & $421.6 \pm 20.3$ & $312.6 \pm 15.1$ & $7.8 \pm 0.2$ & $489.1 \pm 9.6$ & $1559.2 \pm 20.2$ \\
$\mathrm{~A} 2$ & $955.2 \pm 40.7$ & $202.6 \pm 9.1$ & $311.6 \pm 13.3$ & $5.3 \pm 0.1$ & $568.2 \pm 11.9$ & $1492.2 \pm 10.1$ \\
$\mathrm{~A} 3$ & $501.2 \pm 18.2$ & $105.7 \pm 5.6$ & $147.2 \pm 6.1$ & $4.5 \pm 0.1$ & $254.3 \pm 6.2$ & $564.2 \pm 15.4$ \\
$\mathrm{~A} 4$ & $700.2 \pm 21.5$ & $159.5 \pm 8.4$ & $214.7 \pm 15.3$ & $3.2 \pm 0.3$ & $332.2 \pm 4.2$ & $635.2 \pm 8.9$ \\
$\mathrm{~A} 5$ & $821.0 \pm 35.2$ & $203.1 \pm 9.4$ & $187.2 \pm 8.2$ & $9.3 \pm 0.3$ & $269.1 \pm 5.5$ & $653.9 \pm 8.5$ \\
$\mathrm{~A} 6$ & $901.3 \pm 43.7$ & $301.5 \pm 17.3$ & $256.3 \pm 9.1$ & $9.2 \pm 0.1$ & $599.2 \pm 22.2$ & $1569.9 \pm 23.3$ \\
$\mathrm{~A} 7$ & $1299.7 \pm 35.6$ & $319.9 \pm 15.6$ & $301.2 \pm 14.2$ & $9.3 \pm 0.2$ & $654.7 \pm 33.3$ & $1312 \pm 45.6$ \\
$\mathrm{~A} 8$ & $1232.3 \pm 45.3$ & $401.4 \pm 11.1$ & $444.3 \pm 13.3$ & $8.9 \pm 0.1$ & $498.9 \pm 17.1$ & $1589.3 \pm 18.9$ \\
$\mathrm{~A} 9$ & $969.9 \pm 34.1$ & $189.7 \pm 12.4$ & $187.3 \pm 12.0$ & $5.1 \pm 0.1$ & $325.3 \pm 7.8$ & $555.2 \pm 8.2$ \\
$\mathrm{~A} 10$ & $890.1 \pm 33.9$ & $165.4 \pm 10.2$ & $167.4 \pm 8.7$ & $5.3 \pm 0.1$ & $299.1 \pm 12.2$ & $421.7 \pm 10.5$ \\
\hline
\end{tabular}


Table 5. Maximum values of heavy metal in sediments according to US-EPA and NOM147-SEMARNAT/SSA1-2004.

\begin{tabular}{cccc}
\hline \multirow{2}{*}{ Element } & \multicolumn{2}{c}{ US-EPA } & NOM-147-SEMARNAT/ \\
\cline { 2 - 3 } & Moderately Polluted & Heavily Polluted & 22 \\
\hline $\mathrm{As}$ & $2.0-8.0$ & $>8.0$ & 280 \\
$\mathrm{Cr}$ & $25-75$ & $>75$ & 400 \\
$\mathrm{~Pb}$ & $20-200$ & $>200$ & ----- \\
$\mathrm{Co}$ & ---- & ---- & ---- \\
$\mathrm{Mn}$ & 500 & ---- & 1600 \\
$\mathrm{Ni}$ & ----- & ---- & \\
\hline
\end{tabular}

most polluted by As obtained was A7 (1299.7 $\pm 35.6 \mu \mathrm{g} \cdot \mathrm{g}^{-1}$ of As). This value is 5 times more than the permitted maximum contaminant level according to Mexican Standard NOM-147-SEMARNAT/SSA1-2004 (Table 5) [22]. For Cr, the values obtained from sites were $105.7-421.6 \mu \mathrm{g} \cdot \mathrm{g}^{-1}$, which were very similar to those for $\mathrm{Pb}$, where A1, A6, A7, and A8 showed higher levels of pollution. Summary, all sites are highly polluted with $\mathrm{As}, \mathrm{Cr}$, and $\mathrm{Pb}$. Results obtained of $\mathrm{Cr}$ in this work present high pollution at the following sites: A1, A6, A7, and A8. This zone is where San Mateo Atenco, a town where shoes are made, is located, with the presence of a chrome-emitting tannery, thus increasing the chromium concentration in the samples. On the other hand, $\mathrm{Mn}$ and $\mathrm{Ni}$ did not show high concentration at all points compared with $\mathrm{Pb}$, As and $\mathrm{Cr}$. Therefore, $\mathrm{Mn}$ and $\mathrm{Ni}$ can be considered in this study as normal values according to USEPA and NOM-147-SEMARNAT/SSA1-2004. In addition, Co was analyzed, although this is an element that was not considered in either standard. The average of concentration levels of Co obtained at all sites was $<10 \mu \mathrm{g} \cdot \mathrm{g}^{-1}$. This value could be consideration with background level according with NOM-147-SEMARNAP/SSA1-2004.

Today is necessary to develop of analytical methods in sediments, because in recent years, $\mathrm{As}, \mathrm{Cr}$ and $\mathrm{Pb}$ contamination of bodies of water has posed a serious environmental problem internationally. All these species have their own physical and chemical characteristics, resulting in various degrees of mobility according to the properties of the matrix, and then the heavy metals in water can be transferred such as contaminants from water into sediments or vice versa [23] [24] increasing the risk of exposition to the population. In this sense, the contents of heavy metals in sediments are constantly monitored to provide important basic information for environmental assessment.

\section{Conclusion}

The method developed with ICP-OES has been used in lab with routine method, particularly in studies that focus on the impact of pollution on river water. Data obtained in this study indicate that all sites are highly polluted with As, Cr, and $\mathrm{Pb}$ according to USEPA and NOM-147-SEMARNAT/SSA1-2004. ICP-OES is one of the technique qualities for heavy metal measurements in sediments and 
the other complex matrices that have content high of dissolved solids.

\section{Acknowledgements}

We are grateful to the CONACYT-2014, Modalidad A. Establecimiento de Laboratorio Nacional. Project No. 232762 Laboratorio Nacional de Investigación en Forense Nuclear (LANAFONU) and Project ININ/CB-417: CB-417: Desarrollo de Nuevos Métodos Analíticos de Investigación en Forense Nuclear and Project ININ/QU-001: Desarrollo y optimización de métodos analíticos para medir actínidos por técnica de espectrometría de masas y radiométricas for financial support. The authors thank at Ing. Ricardo Soria Juarez by backing in the analysis heavy metals by ICP-OES.

\section{References}

[1] De la Fuente, J.L., Hernández, G. and Marín, L.E. (2000) Heavy Metal Concentration in the Sediments of the Upper Lerma Basin, México. In: Munawar, M., Lawrence, S.G., Munawar, I.F. and Malley, D.F., Eds., Aquatic Ecosytems of México, Bachuys Publisher, Leiden, the Netherlands, 15-27.

[2] Torres, Z., Mora, M.A., Taylor, R.J., Alvarez-Bernal, D., Buelna, H.R. and Hyodo, A. (2014) Accumulation and Hazard Assessment of Mercury to Waterbirds at Lake Chapala, Mexico. Environmental Science \& Technology, 48, 6359-6365. https://doi.org/10.1021/es4048076

[3] Zarazua, G., Ávila-Pérez, P., Tejeda, S., Barcelo-Quintal, I. and Martínez, T. (2006) Analysis of Total and Dissolved Heavy Metals in Surface Water of a Mexican Polluted River by Total Reflection X-Ray Fluorescence Spectrometry. Spectrochimica Acta Part B: Atomic Spectroscopy, 61, 1180-1184.

https://doi.org/10.1016/j.sab.2006.06.010

[4] Jaishankar, M., Tseten, T., Anbalagan, N., Mathew, B.B. and Beeregowda, K.N. (2014) Toxicity, Mechanism and Health Effects of Some Heavy Metals. Interdisciplinary Toxicology, 7, 60-72. https://doi.org/10.2478/intox-2014-0009

[5] Wu, B., Wang, G., Wu, J., Fu, Q. and Liu, C. (2014) Sources of Heavy Metals in Surface Sediments and an Ecological Risk Assessment from Two Adjacent Plateau Reservoirs. PLOS ONE, 9, e102101. https://doi.org/10.1371/journal.pone.0102101

[6] World Health Organization (WHO) (1991) Inorganic Mercury. Environmental Health Criteria, 118.

[7] World Health Organization (WHO) (1995) Lead. Environmental Health Criteria, 165.

[8] World Health Organization (WHO) (2001) Arsenic and Arsenic Compounds. Environmental Health Criteria, 224.

[9] World Health Organization (WHO) (1992) Cadmium. Environmental Health Criteria, 134.

[10] Gorny, J., Lesven, L., Billo, G., Dumoulin, D., Noiriel, C., Pirovano, C. and Madé, B. (2015) Determination of Total Arsenic Using a Novel Zn-Ferrite Binding Gel for DGT Techniques: Application to the Redox Speciation of Arsenic in River Sediments. Talanta, 144, 890-898. https://doi.org/10.1016/j.talanta.2015.07.016

[11] Yang, C., Li, S., Liu, R., Sun, P. and Liu, K. (2015) Effect of Reductive Dissolution of Iron (Hydr)Oxides on Arsenic Behavior in a Water-Sediment System: First Release, then Adsorption. Ecological Engineering, 83, 176-183. 
https://doi.org/10.1016/j.ecoleng.2015.06.018

[12] Zan, F., Huo, S., Zhang, J., Zhang, L., Xi, B. and Zhang, L. (2014) Arsenic Fractionation and Contamination Assessment in Sediments of Thirteen Lakes from the East Plain and Yungui Plateau Ecoregions, China. Journal of Environmental Sciences, 26, 1977-1984. https://doi.org/10.1016/j.jes.2014.07.010

[13] Dumcius, A., Paliulis, D. and Kozlovska-Kedziora, J. (2001) Selection of Investigation Methods for Heavy Metal Pollution on Soil and Sediments of Water Basins and River Bottoms: A Review. Ekologija, 52, 30-38.

[14] He, C.-T., Zheng, X.-B., Yan, X., Zheng, J., Wang, M.-H., Tan, X., Qiao, L., Chen, S.-J., Yang, Z.-Y. and Mai, B.-X. (2017) Organic Contaminants and Heavy Metals in Indoor Dust from E-Waste Recycling, Rural, and Urban Areas in South China: Spatial Characteristics and Implications for Human Exposure. Ecotoxicology and Environmental Safety, 140, 109-115. https://doi.org/10.1016/j.ecoenv.2017.02.041

[15] Yin, Y.G., Liu, J.F., He, B., Shi, J.B. and Jiang, G.B. (2008) Simple Interface of HighPerformance Liquid Chromatography-Atomic Fluorescence Spectrometry Hyphenated System for Speciation of Mercury Based on Photo-Induced Chemical Vapour Generation with Formic Acid in Mobile Phase as Reaction Reagent. Journal of Chromatography: A, 1181, 77-82. https://doi.org/10.1016/j.chroma.2007.12.050

[16] Tuzen, M. (2003) Determination of Heavy Metals in Soil, Mushroom and Plant Samples by Atomic Absorption Spectrometry. Microchemical Journal, 74, 289-297. http://doi.org/10.1016/S0026-265X(03)00035-3

[17] Dimpe, K.M., Ngila, J.C., Mabuba, N. and Nomngongo, P.N. (2014) Evaluation of Sample Preparation Methods for the Detection of Total Metal Content Using Inductively Coupled Plasma Optical Emission Spectrometry (ICP-OES) in Wastewater and Sludge. Physics and Chemistry of the Earth, 76, 42-48. https://doi.org/10.1016/j.pce.2014.11.006

[18] Boss, C.B. and Fredeen, K.J. (2004) Chapter 4 Concepts, Instrumentation and Techniques in Inductively Coupled Plasma Optical Emission Spectrometry. 3rd Edition, PerkinElmer, Inc., USA.

[19] Silva, F.V., Trevizan, L.C., Silva, C.S., Nogueira, A.R.A. and Nóbrega, J.A. (2002) Evaluation of Inductively Coupled Plasma Optical Emission Spectrometers with Axially and Radially Viewed Configurations. Spectrochimica Acta Part B: Atomic Spectroscopy, 57, 1905-1913. https://doi.org/10.1016/S0584-8547(02)00176-3

[20] United States Environmental Protection Agency (USEPA) (1977) Guidelines for the Pollutional Classification of Great Lake Harbor Sediments. Region 5, USEPA, Chicago, IL.

[21] United States Environmental Protection Agency (USEPA) (2011) Edition of the Drinking Water Standards and Health Advisories. Office of Water U.S. USEPA, Washington, DC. 719-726, 731-732.

[22] NOM-147-SEMARNAT/SSA1-2004 (2007) Norma Oficial Mexicana que establece criterios para determinar las concentraciones de remediación de suelos contaminados por arsénico, berilio, cadmio, cromo hexavalente, mercurio, níquel, plomo, selenio, talio y vanadio. NOM-147-SEMARNAT/SSA1-2004, Diario oficial de la Federación (DOF), 41.

[23] Aebischer, S., Cloquet, C., Carignan, J., Maurice, C. and Pienitz, R. (2015) Disruption of the Geochemical Metal Cycle during Mining: Multiple Isotope Studies of Lake Sediments from Schefferville, Subarctic Québec. Chemical Geology, 412, 162178. https://doi.org/10.1016/j.chemgeo.2015.07.028 
[24] Wang, Z., Wang, Y., Chen, L., Yan, C., Yan, Y. and Chi, Q. (2015) Assessment of metal Contamination in Coastal Sediments of the Maluan Bay (China) Using Geochemical Indices and Multivariate Statistical Approaches. Marine Pollution Bulletin, 99, 43-53. http://doi.org/10.1016/j.marpolbul.2015.07.064 